\title{
The Effect of Olanzapine Treatment on Monoamine Metabolite Concentrations in the Cerebrospinal Fluid of Schizophrenic Patients
}

Floortje E. Scheepers, M.D., Christine C. Gispen-de Wied, M.D., Ph.D., Herman G. M. Westenberg, Ph.D., and René S. Kahn, M.D., Ph.D.

The mechanism of action of both typical antipsychotics and the atypical antipsychotic, clozapine, may be related to the (changing) interaction of dopamine and serotonin in schizophrenia. This study examined the effect of olanzapine in schizophrenic patients on cerebrospinal fluid (CSF) metabolites of dopamine (homovanillic acid, HVA) and serotonin (5-hydroxyindoleacetic acid, 5-HIAA). Twentythree male schizophrenic patients, who were drug-free for at least 2 weeks (mean drug-free period of 35 days \pm 43 ; median 16 days), underwent a lumbar puncture ( $L P)$. Patients were subsequently treated with olanzapine $10 \mathrm{mg} /$ day for 6 weeks, after which the LP was repeated. CSF was assayed for HVA and 5-HIAA concentrations. Psychiatric symptoms were rated once a week. Olanzapine significantly increased HVA concentrations and the HVA/5-HIAA ratio while 5-HIAA concentrations were not altered. These changes did not significantly correlate with treatment response. A negative correlation was found between HVA concentrations and negative symptoms after olanzapine treatment. In conclusion, olanzapine treatment increases HVA concentrations and the HVA/5-HIAA ratio in CSF of schizophrenic patients, but these changes are unrelated to its clinical efficacy.

[Neuropsychopharmacology 25:468-475, 2001] (C) 2001 American College of Neuropsychopharmacology. Published by Elsevier Science Inc. All rights reserved.
KEY WORDS: Olanzapine; Dopamine; Serotonin; Cerebrospinal Fluid

It has long been postulated that the mechanism of action of antipsychotics is related to their ability to block dopamine $_{2}\left(\mathrm{DA}_{2}\right)$ receptors (Creese et al. 1976; Carlsson 1978; Farde et al. 1988). However, since the introduction of the atypical antipsychotics, most notably clozapine, it

From the Department of Psychiatry, University Medical Center, Utrecht, The Netherlands.

Address correspondence to: F. E. Scheepers, M.D., University Medical Center, Department of Psychiatry (A00.214), P.O. Box 85500, 3508 GA Utrecht, The Netherlands. Tel.: +31-30-2508180; Fax: +31-30-2505443; E-mail: fscheepers@psych.azu.nl

Received August 10, 2000; revised December 5, 2000; accepted March 7, 2001.

Online publication: 3/9/01 at www.acnp.org/citations/Npp 03090189. has become clear that $\mathrm{DA}_{2}$ receptor blockade alone is insufficient to explain the clinical potency of all antipsychotic drugs (Meltzer 1989; Davis et al. 1991; Lieberman et al. 1998). Instead, it has been proposed that the mechanism of action of antipsychotics is rooted in their ability to affect both DA and serotonin (5-hydroxytryptamine, 5-HT) systems in the brain or, more specifically, their interaction (Meltzer 1989; Hsiao et al. 1993a; Kahn et al. 1993; Szymanski et al. 1993; Schmidt et al. 1995; Kapur and Remington 1996; Lieberman et al. 1998). Indeed, DA and 5-HT are functionally (Agren et al. 1986; Risby et al. 1987; Kelland et al. 1990; Roth and Meltzer 1995; Iyer and Bradberry 1996; Lieberman et al. 1998;) and anatomically (Ternaux et al. 1977; Priestley et al. 1981; Hetey and Drescher 1986; Fibiger and Miller 1987; Törk 1991) strongly related and thus may hardly be regarded independently. 
One way to examine DA and 5-HT systems in the brain is through measurement of their metabolites in cerebrospinal fluid (CSF), that is, homovanillic acid (HVA) and 5-hydroxyindole-acetic acid (5-HIAA), respectively. Several studies (Garelis and Sourkes 1973; Weir et al. 1973; Wood 1980; Andersen et al. 1981; Bertilsson et al. 1982; Stanley et al. 1985; Wester et al. 1990; cf. Banki and Molnar 1981; Potter and Manji 1993) have demonstrated that concentrations of HVA and 5-HIAA in CSF reliably reflect HVA and 5-HIAA concentrations in the brain. This suggests that CSF HVA and 5-HIAA concentrations reflect central DA and 5-HT turnover and thus can be used to examine the effects of antipsychotic drugs on these two neurotransmitters and their ratio in vivo (Agnati et al. 1995; Silver et al. 1996).

It has been shown that typical antipsychotics, which predominantly block $\mathrm{DA}_{2}$ receptors, increase CSF HVA concentrations (Wode-Helgodt et al. 1977; Härnryd et al. 1984; Sharma et al. 1989; Hsiao et al. 1993b; Kahn et al. 1993; Wieselgren and Lindstrom 1998;) and the HVA/5-HIAA ratio (Wode-Helgodt et al. 1977; Härnryd et al. 1984; Hsiao et al. 1993b; Kahn et al. 1993) without significantly affecting CSF 5-HIAA concentrations. Interestingly, the increase of the HVA/5-HIAA ratio (Kahn et al. 1993; Wieselgren and Lindstrom 1998), but not the increase of the HVA concentrations (Sedvall et al. 1974; Kahn et al. 1993; Sharma et al. 1993), was found to be related to symptomatic improvement after treatment with typical antipsychotics, suggesting that the therapeutic effect of these antipsychotics is associated with changing DA function relative to 5-HT function, rather than changing DA function per se. Studies examining the effects of the atypical antipsychotics on CSF monoamine metabolites in schizophrenia are lacking, except for a few studies investigating clozapine's impact on these metabolites in refractory patients (Banki 1978; Hsiao et al. 1993b; Szymanski et al. 1993; Risch and Lewine 1995) or in childhood onset schizophrenia (Jacobsen et al. 1997). In these studies, clozapine failed to alter CSF HVA and 5-HIAA concentrations or the HVA/5-HIAA ratio. However, it was reported that patients who respond well to clozapine display lower pretreatment CSF HVA/5-HIAA ratios than patients who do not respond to clozapine (Pickar et al. 1992; Risch and Lewine 1993; Szymanski et al. 1993; Lieberman et al. 1994; Risch and Lewine 1995;). This suggests that, again, the DA/5-HT ratio is important with respect to (in this case in predicting) treatment response.

This study examined the effect of the atypical antipsychotic olanzapine on HVA and 5-HIAA concentrations and their ratio in CSF in a non-refractory group of schizophrenic patients. We hypothesized that treatment with olanzapine would alter the HVA/5-HIAA ratio and that this change (or the pretreatment HVA/5HIAA ratio) would be related to treatment response.

\section{METHODS}

\section{Subjects}

Twenty-three male schizophrenic patients (mean age $=$ 31.0 years, $\mathrm{SD}=8.8$; mean duration of illness 80.4 months, $\mathrm{SD}=78.3$ ) participated in this study. During the study all patients were treated as inpatients at the University Medical Center in Utrecht. After the study they were all treated as outpatients. Upon entry into the study, patients were evaluated using the Comprehensive Assessment for Symptoms and History (CASH) interview (Andreasen et al. 1992), and met DSM-IV criteria for schizophrenia paranoid type $(n=15)$, disorganized type $(\mathrm{n}=4)$, undifferentiated type $(\mathrm{n}=1)$, schizophreniform disorder $(\mathrm{n}=1)$, or schizoaffective disorder $(n=2)$. The CASH interview was performed by two trained raters who independently determined the diagnosis and afterwards achieved consensus. All patients had normal results for laboratory and physical examinations and were free of alcohol or drug abuse, according to DSM-IV criteria, for at least 3 months. Subjects with medical illness, or who used depot medication within 2 months before the study entry were excluded from participation. Patients were previously treated with typical antipsychotics $(\mathrm{n}=6)$, atypical antipsychotics $(n=5)$, both typical and atypical antipsychotics $(n=5)$, or had no prior antipsychotic treatment $(n=7)$. One patient, who had been previously treated with typical and atypical antipsychotics, had been drug free for 12 years prior to the study. Five patients did not complete the study because they refused further participation $(n=4)$, or needed corticosteroids to treat a somatic disorder $(n=1)$. After a complete description of the study, written informed consent was obtained from all subjects prior to participation.

\section{Procedure}

Psychopathology, duration of illness, and prior medication history were assessed using the CASH interview and the Positive and Negative Symptom Scale (PANSS; Kay et al. 1987). Patients who were on antipsychotic medication $(\mathrm{n}=15)$ were withdrawn from it and remained free of antipsychotic medication for at least 2 weeks before the LP (mean duration of the drug-free period was 35 days, $\mathrm{SD}=43$, median of 16 days). Up to $40 \mathrm{mg}$ /day diazepam equivalents were allowed for insomnia or agitation throughout the study. No other medication was allowed. Following the drug-free period, patients underwent an LP after maintaining bed rest and fasting (except for water) from 23:00 before the procedure. The LP was performed between 09:00 and 10:00 with patients in the lateral decubitus position. Eleven drops $(0.5 \mathrm{ml})$ of CSF were collected into tubes by a standard procedure, gently mixed, transported in dry ice, and stored at $-70^{\circ} \mathrm{C}$ until analysis. Within 1 
week following the LP, patients were treated with 10 mg olanzapine daily for 6 weeks. During the sixth week of treatment with olanzapine, the LP was repeated. The PANSS was rated, by trained raters, on the day olanzapine was started (baseline) and then weekly during treatment with the antipsychotic. Interrater reliability was $r=0.95$. A $20 \%$ or greater reduction in total PANSS scores from baseline to week 6 was defined a priori as treatment response, while lack of such a change was defined as treatment nonresponse.

\section{Biochemical Analysis}

CSF 5-HIAA and HVA were analyzed by means of liquid chromotography, as desribed previously (Westenberg and Verhoeven 1988). Briefly, after thawing, $25 \mu \mathrm{L}$ CSF was centrifuged at $1200 \mathrm{~g}$ for $2 \mathrm{~min}$, and the supernatant was injected into the liquid chromatograph. Separation was performed on a YMC-pack ODS column (Inacom Instruments, Amsterdam, The Netherlands) using a mobile phase consisting of $0.05 \mathrm{M}$ acetate buffer $(\mathrm{pH}=4), 12.5 \%$ methanol, $30 \mathrm{mg} / \mathrm{L}$ heptanesulfonic acid, and $100 \mathrm{mg} / \mathrm{L}$ EDTA. The components were separated at $40^{\circ} \mathrm{C}$ and detected with an electrochemical detector (Antec, Amsterdam, The Netherlands) at a potential of $800 \mathrm{mV}$. The data were analyzed using a Chromeleon Chromatographic Data system. Calibration was achieved by analyzing CSF samples supplemented with known amounts of the compounds of interest. The sensitivity of the method is $1 \mathrm{fmol} /$ L CSF for both compounds and the inter- and intra-coefficients of variations were $6 \%$ and $5 \%$, respectively.

\section{Data Analysis}

The effects of olanzapine treatment on CSF metabolites were analyzed using paired $t$ tests. Variables used were HVA and 5-HIAA concentrations and the HVA/5HIAA ratio. To examine the relationship between HVA and 5-HIAA concentrations, before and after treatment with olanzapine, Pearson correlations were performed. Change of symptomatology during treatment with olanzapine was calculated using repeated measures ANOVA on PANSS scores with the factor "Time" (7 levels: baseline, week 1 , week 2 , week 3 , week 4 , week 5 , and week 6). To correlate HVA and 5-HIAA concentrations, and the HVA/5-HIAA ratio, before and after treatment, with symptoms at that time, partial correlations were used. Pearson correlations were used to examine the relationship between changes in symptomatology $\left(\triangle \mathrm{PANSS}=\mathrm{PANSS}_{\text {before treatment }}-\mathrm{PANSS}_{\text {after }}\right.$ treatment $)$ and changes in HVA concentrations $(\triangle \mathrm{HVA}=$ $\left.\mathrm{HVA}_{\text {before treatment }}-\mathrm{HVA}_{\text {after treatment }}\right)$, 5-HIAA concentrations $\left(\Delta 5\right.$-HIAA $=5$-HIAA before treatment -5 -HIAA $\mathrm{H}_{\text {after treat- }}$ ment), and the HVA/5-HIAA ratio ( $\triangle \mathrm{HVA} / 5$-HIAA =

Table 1. CSF HVA, 5-HIAA, and HVA/5-HIAA Ratio before and after Treatment with Olanzapine

\begin{tabular}{|c|c|c|c|c|c|c|}
\hline \multirow[b]{2}{*}{ Patient Number } & \multicolumn{2}{|c|}{ HVA $\mu \mathrm{g} / \mathrm{L}$} & \multicolumn{2}{|c|}{ 5-HIAA $\mu \mathrm{g} / \mathrm{L}$} & \multicolumn{2}{|c|}{ HVA/5-HIAA } \\
\hline & Before & After & Before & After & Before & After \\
\hline 1 & 44.9 & 48.5 & 16.9 & 13.7 & 2.66 & 3.54 \\
\hline 2 & 14.2 & - & 4.8 & - & 2.96 & - \\
\hline 3 & 33.9 & 48.5 & 14.5 & 18.4 & 2.34 & 2.64 \\
\hline 4 & 11.5 & 19.2 & 4.4 & 5.4 & 3.38 & 3.56 \\
\hline 5 & 8.0 & 7.8 & 5.4 & 2.3 & 1.48 & 3.39 \\
\hline 6 & 23.9 & - & 7.7 & - & 3.10 & - \\
\hline 7 & 11.0 & 9.5 & 6.5 & 5.0 & 1.69 & 1.90 \\
\hline 8 & 14.7 & 9.1 & 7.1 & 2.8 & 2.07 & 3.25 \\
\hline 9 & 10.9 & 9.5 & 5.4 & 3.4 & 2.02 & 2.79 \\
\hline 10 & 17.5 & 42.6 & 5.6 & 11.9 & 3.13 & 3.58 \\
\hline 11 & 13.9 & 22.3 & 6.6 & 8.3 & 2.11 & 2.69 \\
\hline 12 & 6.5 & 15.3 & 2.7 & 7.3 & 2.41 & 2.10 \\
\hline 13 & 14.6 & 20.3 & 3.5 & 4.1 & 4.17 & 4.95 \\
\hline 14 & 14.1 & 15.9 & 10.3 & 10.6 & 1.37 & 1.50 \\
\hline 15 & 18.8 & 19.7 & 12.8 & 10.0 & 1.47 & 1.97 \\
\hline 16 & 10.0 & - & 8.3 & - & 1.20 & - \\
\hline 17 & 18.0 & 34.2 & 11.4 & 19.0 & 1.58 & 1.80 \\
\hline 18 & 15.4 & 18.7 & 11.0 & 9.5 & 1.40 & 1.97 \\
\hline 19 & 27.9 & 38.4 & 14.2 & 14.7 & 1.96 & 2.61 \\
\hline 20 & 19.9 & 22.2 & 9.2 & 10.0 & 2.16 & 2.22 \\
\hline 21 & 24.9 & 24.8 & 10.0 & 7.6 & 2.49 & 3.26 \\
\hline 22 & 6.7 & - & 4.8 & - & 1.40 & - \\
\hline 23 & 25.5 & - & 11.7 & - & 2.18 & - \\
\hline Mean & 17.7 & 23.7 & 8.4 & 9.1 & 2.2 & 2.8 \\
\hline SD & 9.2 & 13.3 & 3.9 & 5.0 & 0.8 & 0.9 \\
\hline
\end{tabular}

$\mathrm{SD}=$ standard deviation 
HVA/5-HIAA before treatment $-\mathrm{HVA} / 5-\mathrm{HIAA}_{\text {after treatment }}$ ). Independent $t$ tests were used to compare CSF metabolite changes between responders and nonresponders to treatment with olanzapine. Multiple regression analysis was performed to investigate the predictive value of HVA and 5-HIAA concentrations, and the HVA/5HIAA ratio with respect to clinical response (HVA, 5-HIAA, and HVA/5-HIAA before treatment as independent values, $\triangle$ PANSS as dependent value).

Data were also examined through multiple regression using a multivariate general linear model with final ratings of the total PANSS, positive, negative, and general symptoms of the PANSS as dependent variable and initial ratings of the corresponding measures, baseline HVA concentrations (or baseline 5-HIAA concentrations or the baseline HVA/5-HIAA ratio), and final HVA concentrations (or final 5-HIAA concentrations or the final HVA/5HIAA ratio) as covariates. The same analysis was used to predict final ratings of the PANSS (dependent variable) from initial PANSS ratings and initial HVA, 5-HIAA levels and the initial HVA/5-HIAA ratio (covariates).

Pearson correlations were used to examine the relationship between CSF variables and pre-study status of the patients (i.e., age, weight, smoking, illness duration, and prior typical, atypical, or combined antipsychotic treatment).

\section{RESULTS}

Olanzapine treatment significantly increased HVA concentrations $(\mathrm{t}=-3.127, \mathrm{df}=1 ; 17, p<.01)$ and the
HVA/5-HIAA ratio $(\mathrm{t}=-4.704, \mathrm{df}=1 ; 17, p<.001)$, but did not affect 5-HIAA concentrations $(\mathrm{t}=-.516$, $\mathrm{df}=1 ; 17, p=.612$ ) (Table 1).

HVA and 5-HIAA concentrations were significantly correlated before treatment $(\mathrm{r}=.824, p<.001)$ and after treatment with olanzapine $(\mathrm{r}=.841, p<.001)$.

Patients significantly improved during treatment with olanzapine, as was demonstrated by a decrease in the PANSS score over time (total PANSS score: $\mathrm{F}=$ $5.666, \mathrm{df}=6 ; 12, p<.01$; positive symptoms: $\mathrm{F}=3.608$, $\mathrm{df}=6 ; 12, p<.05$; negative symptoms: $\mathrm{F}=3.737, \mathrm{df}=$ $6 ; 12, p<.05$; general symptoms: $\mathrm{F}=5.101, \mathrm{df}=6 ; 12$, $p<.01)$.

After treatment, negative symptoms of the PANSS were significantly correlated with HVA concentrations (HVA after treatment: $\mathrm{r}=-.591, p<.01$ ) (Figure 1), but not with 5-HIAA or the HVA/5-HIAA ratio. No significant correlations were found for negative symptoms with CSF metabolites before treatment with olanzapine. Also no significant correlations were found for positive or general symptoms of the PANSS with the CSF metabolites or their ratio.

Change in PANSS score was not significantly related to change in HVA concentrations $(\mathrm{r}=-.070, p=.783)$ or change in the ratio of HVA/5-HIAA ( $\mathrm{r}=-.345, p=$ .161). No differences were found between responders $(\mathrm{n}=10)$ and nonresponders $(\mathrm{n}=8)$ to olanzapine treatment in change in HVA concentrations $(\mathrm{t}=.013, \mathrm{df}=$ $2 ; 16, p=.990$ ) or in change in the HVA/5-HIAA ratio $(\mathrm{t}=.150, \mathrm{df}=2 ; 16, p=.882)$. Pretreatment HVA concentrations, 5-HIAA concentrations, nor the HVA/5HIAA ratio were significantly related to treatment re-

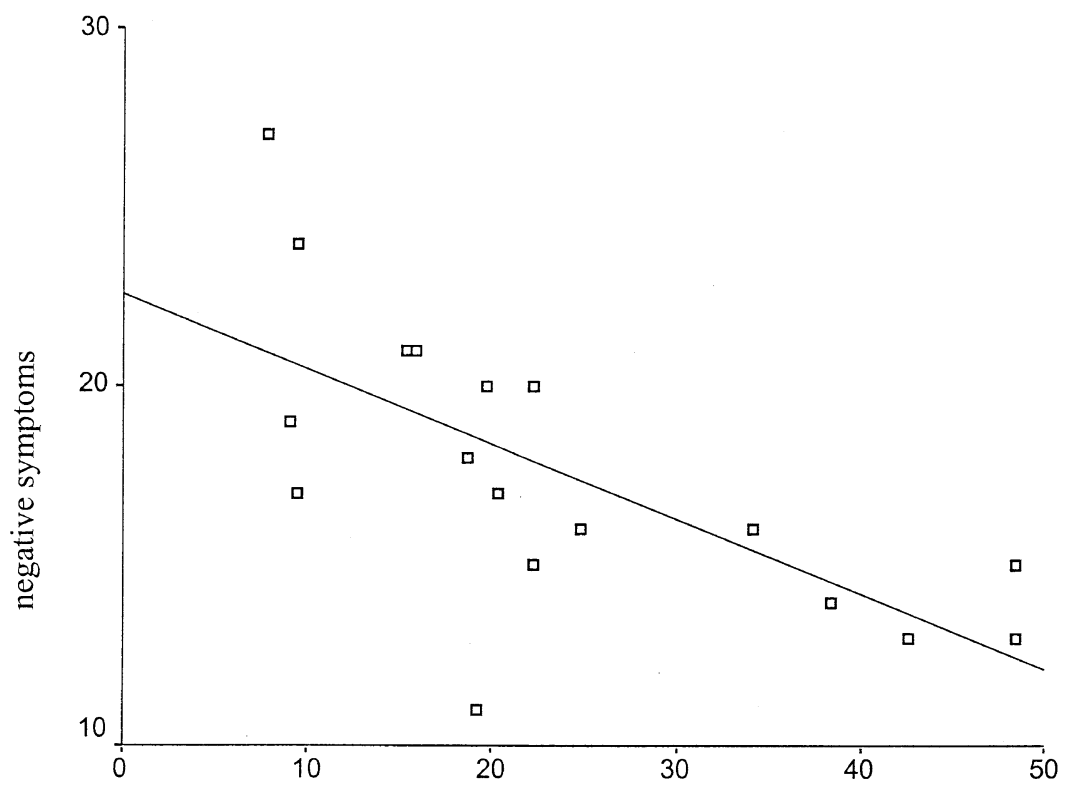

Figure 1. Relationship between negative symptoms and HVA after olanzapine treatment $(\mathrm{n}=18)$. 
sponse in a multiple regression analysis (ANOVA: $\mathrm{F}=$ $1.04, \mathrm{df}=3 ; 15, p=.40$ ).

No significant correlations were found between final HVA concentrations, 5-HIAA concentrations or their ratio with final PANSS ratings in a multiple regression (HVA: $\mathrm{F}=3.125, \mathrm{df}=3 ; 10, p=.075 ; 5$-HIAA: $\mathrm{F}=$ 1.109, $\mathrm{df}=3 ; 10, p=.391$; HVA/5-HIAA: $\mathrm{F}=0.11, \mathrm{df}=$ $3 ; 10, p=.952)$. Correlations of HVA concentrations, 5-HIAA concentrations or their ratio with total PANSS score, positive, negative, and general symptoms of the PANSS separately also were not significant, except the correlation between final HVA concentration and final negative symptoms of the PANSS $(\mathrm{F}=8.727, \mathrm{df}=1 ; 17$, $p=.012)$. Final total PANSS score, and final positive, negative, and general symptoms of the PANSS were not significantly predicted from initial HVA concentrations, 5-HIAA concentrations, or their ratio in a multiple regression (HVA: $\mathrm{F}=0.654, p=.598,5$-HIAA: $\mathrm{F}=$ $.312, p=.817$, HVA/5-HIAA: $\mathrm{F}=.076, p=.972$ ).

No significant correlations were found between CSF variables and pre-study status of the patients.

\section{DISCUSSION}

Treatment with olanzapine resulted in a significant increase in CSF HVA concentrations and the HVA/ 5-HIAA ratio, while 5-HIAA concentrations were not altered. Olanzapine treatment significantly reduced positive and negative symptoms in these patients. However, no relationship between changes in CSF metabolites and improvement of symptoms was found.

Increases in CSF HVA concentrations and the HVA/ 5-HIAA ratio have also been reported after treatment with typical antipsychotics (Wode-Helgodt et al. 1977; Härnryd et al. 1984; Sharma et al. 1989; Hsiao et al. 1993b; Kahn et al. 1993; Wieselgren and Lindstrom 1998) but not after treatment with the atypical antipsychotic clozapine (Banki 1978; Hsiao et al. 1993b; Szymanski et al. 1993; Risch and Lewine 1995; Jacobsen et al. 1997). However, in contrast to the studies with typical antipsychotics and the present study, patients in the clozapine studies were treatment refractory (Banki 1978; Hsiao et al. 1993b; Szymanski et al. 1993; Risch and Lewine 1995) or childhood onset (Jacobsen et al. 1997) and thus may represent a different group of schizophrenic patients. Hence, it is possible that in a non-treatment refractory sample of schizophrenic patients typical and atypical antipsychotics have the same effect on HVA concentrations and the HVA/5-HIAA ratio in CSF.

The relationship between an increase in the HVA/5HIAA ratio in CSF and symptom improvement after treatment with typical antipsychotics (Kahn et al. 1993; Wieselgren and Lindstrom 1998) was not replicated in the present study suggesting that, unlike typical antipsychotics, the clinical effect of olanzapine is not related to the increase of dopamine turnover in the brain relative to that of serotonin. Furthermore, the correlation between a low pretreatment CSF HVA/5-HIAA ratio and treatment response to clozapine (Pickar et al. 1992; Risch and Lewine 1993; Szymanski et al. 1993; Lieberman et al. 1994; Risch and Lewine 1995), once again, may apply only to treatment refractory schizophrenic patients, which could explain why studies with typical antipsychotics, and the present study with olanzapine (all conducted in non-refractory patients), found no significant correlation between the pretreatment HVA/ 5-HIAA ratio and symptom improvement. Moreover, different procedures used in the clozapine studies (i.e., duration of treatment, method of analysis, criteria of response) make it difficult to compare these studies with the present findings.

There are several complications in interpreting CSF monoamine metabolite measurements (Amin et al. 1992; Lieberman and Koreen 1993; Potter and Manji 1993). For example, acidic metabolites are transported across the brain-blood barrier by a probenecid sensitive organic anion transport system in rat brain (Westerlink and Kikkert 1986). Olanzapine (like haloperidol) may inhibit this system resulting in an increase of metabolites. However, in our study, only HVA concentrations increased while 5-HIAA concentrations were unchanged, and HVA and 5-HIAA remained strongly related. This suggests that a change in clearance of metabolites by a common acid transport mechanism out of CSF (which would have resulted in an increase of both HVA and 5-HIAA) could not explain the increased HVA concentrations, as was supported by some (Agren et al. 1986; Jibson et al. 1990). Other factors play a role in monoamine metabolite concentrations in CSF like age (Asberg 1994), smoking (Geracioti et al. 1999), stress (Hill et al. 1999), and body weight (Nordin et al. 1995), which could have influenced our data. However, we found no significant differences between smokers and non-smokers and no significant correlations between age or body weight and CSF monoamine metabolites.

Apart from these considerations, it has been suggested that CSF HVA and 5-HIAA concentrations do not reflect dopamine and serotonin turnover in the whole brain but merely in specific brain regions (i.e., frontal and prefrontal cortex or striatum) (Stanley et al. 1985; Agren et al. 1986; van Kammen et al. 1986; Doran et al. 1987; Elsworth et al. 1987; Wester et al. 1990). It could therefore be possible that the clinical efficacy of olanzapine is (partially) related to its effect on dopamine and serotonin receptors in brain regions that do not contribute to the monoamine metabolites in CSF.

Despite the serotonin antagonistic property of olanzapine (Moore et al. 1997; Bymaster et al. 1999), no sig- 
nificant alterations of CSF 5-HIAA concentrations were found in the present study. Interestingly, similar findings were obtained when clozapine, also a potent 5-HT antagonist (Kahn et al. 1994a), was used, suggesting that CSF 5-HIAA concentrations may not be a potent marker for central 5-HT turnover, as has indeed been proposed (Eklundh et al. 1996). Moreover, because it is shown that the selective serotonin antagonist, ritanserin, does not alter CSF 5-HIAA concentrations (Wiesel et al. 1994), it may be argued that CSF 5-HIAA concentrations are less suitable to measure the serotonin antagonistic effects of antipsychotics. Thus, treatment response to atypical antipsychotics may not be investigated properly through measurement of CSF HVA and 5-HIAA concentrations because the clinical potency of these antipsychotics appears, in part, to be the result of the antagonistic effect on serotonin receptors (Moore et al. 1994; Lieberman et al. 1998). Alternatively, other neurotransmitter systems, such as the norepinephrine or glutamate system, are affected by treatment with olanzapine (Moore et al. 1997; Bymaster et al. 1999), which possibly contributes to olanzapine's clinical efficacy. However, conclusions about the relationship between CSF metabolites and response to olanzapine must be drawn with caution because of the small number of patients in this study.

The negative correlation between HVA concentrations and the negative symptoms of the PANSS after treatment with olanzapine, replicates previous CSF studies in which it was suggested that decreased dopamine turnover in (the frontal cortex of) the brain is associated with negative symptoms of schizophrenia (Lindstrom 1985; Weinberger et al. 1988; Kahn et al. 1994b). Our findings therefore strengthen the presumption that DA plays a role in the negative symptom complex of schizophrenia (Meltzer 1989; Davis et al. 1991; Duinkerke et al. 1993; Szymanski et al. 1993).

To conclude, this study found that, although treatment with the atypical antipsychotic olanzapine increased CSF HVA concentrations and the HVA/ 5-HIAA ratio, this effect was not related to treatment response. This suggests that, in a non-refractory sample of schizophrenic patients, the clinical potency of olanzapine may result from its effect on brain regions and/or neurotransmitter systems other than those represented by CSF HVA and 5-HIAA concentrations or their ratio alone. The negative correlation between HVA concentrations and negative symptoms of the PANSS suggests that decreased DA turnover is related to the negative symptom complex of schizophrenia.

\section{ACKNOWLEDGMENTS}

This study was supported by Eli Lilly International, clinical research. We thank H. J. Wynne, Ph.D., for his statistical advice.

\section{REFERENCES}

Agnati LF, Zoli M, Stromberg I, Fuxe K (1995): Intercellular communication in the brain: wiring versus volume transmission. Neuroscience 69:711-726

Agren H, Mefford IN, Rudorfer MV, Linnoila M, Potter WZ (1986): Interacting neurotransmitter systems: a nonexperimental approach to the 5HIAA-HVA correlation in human CSF. J Psychiatry Res 20:175-193

Amin F, Davidson M, Davis KL (1992) : Homovanillic acid measurement in clinical research : a review of methodology. Schizophr Bull 18:123-141

Andersen O, Johansson B, Svennerholm L (1981): Monoamine metabolites in successive samples of spinal fluid. Acta Neurol Scand 63:247-254

Andreasen NC, Flaum M, Arndt S (1992): The comprehensive Assessment of Symptoms and History (CASH). An instrument for assessing diagnosis and psychopathology. Arch Gen Psychiatry 49:615-623

Asberg M (1994): Monoamine neurotransmitters in human aggressiveness and violence: A selective review. Crim Behav Ment Health 4:303-327

Banki CM (1978): Alterations of cerebrospinal fluid 5-hydroxyindoleacetic acid, and total blood serotonin content during clozapine treatment. Psychopharmacology 56: 195-198

Banki CM, Molnar G (1981): Cerebrospinal fluid 5-hydroxyindoleacetic acid as an index of serotonergic processes. Psychiatry Res 5:23-32

Bertilsson L, Asberg M, Lantto O, Scalia-Tomba GP, Traskman-Bendz L, Tybring G (1982): Gradients of monoamine metabolites and cortisol in cerebrospinal fluid of psychiatric patients and healthy controls. Psychiatry Res 6:77-83

Bymaster F, Perry KW, Nelson DL, Wong DT, Rasmussen K, Moore NA, Calligaro DO (1999): Olanzapine: a basic science update. Br J Psychiatry 174(suppl 37):36-40

Carlsson A (1978): Antipsychotic drugs, neurotransmitters, and schizophrenia. Am J Psychiatry 135:164-173

Creese J, Burt DR, Snyder SH (1976): Dopamine receptor binding predicts clinical pharmacological potencies of anti-schizophrenic drugs. Science 192:481-483

Davis KL, Kahn RS, Ko G, Davidson M (1991): Dopamine in schizophrenia: a review and reconceptualization. Am J Psychiatry 148:1474-1486

Doran AR, Boronow J, Weinberger DR, Wolkowitz OM, Breier A, Pickar D (1987): Structural brain pathology in schizophrenia revisited: prefrontal cortex pathology is inversely correlated with cerebrospinal fluid levels of homovanillic acid. Neuropsychopharmacology 1:25-32

Duinkerke SJ, Botter PA, Jansen AA, van Dongen PA, van Haaften AJ, Boom AJ, van Laarhoven JH, Busard HL (1993): Ritanserin a selective 5-HT2/1c antagonist and negative symptoms in schizophrenia. A placebo controlled double blind trial. Br J Psychiatry 163:451-455

Eklundh T, Eriksson M, Sloberg S, Nordin C (1996): Monoamine precursors, transmitters and metabolites in cerebrospinal fluid: a prospective study in healthy male subjects. J Psychiat Res 30:201-208

Elsworth JD, Leahy DJ, Roth RH, Redmond Jr DE (1987): 
Homovanillic acid concentrations in brain, CSF and plasma as indicators of central dopamine function in primates. J Neural Transm 68:51-62

Farde L, Wiesel FA, Halldin C, Sedvall G (1988): Central D2dopamine receptor occupancy in schizophrenic patients treated with antipsychotic drugs. Arch Gen Psychiatry 20:513-517

Fibiger HC, Miller JJ (1987): An anatomical and electrophysiological investigation of the serotonergic projection from the dorsal raphe nucleus to the substantia nigra in the rat. Neuroscience 2:975-987

Garelis E, Sourkes TL (1973): Sites of origin in the central nervous system of monoamine metabolites measured in human cerebrospinal fluid. J Neurosurg Psychiat 36: 625-629

Geracioti TD, West SA, Baker DG, Hill KK, Ekhator NN, Wortman MD, Keck PE, Norman AB (1999): Low CSF concentration of a dopamine metabolite in tobacco smokers. Am J Psychiatry 156:130-132

Härnryd C, Bjerkenstedt L, Gullberg B, Oxenstierna G, Sedvall G, Wiesel FA (1984): Time course for effects of sulpiride and chlorpromazine on monoamine metabolite and prolactin levels in cerebrospinal fluid from schizophrenic patients. Acta Psychiatr Scand 311:S75S92

Hetey L, Drescher K (1986): Influence of antipsychotics on presynaptic receptors modulating the release of dopamine synaptosomes of the nucleus accumbens of rats. Neuropharmacology 25:1103-1109

Hill KK, West SA, Ekhator NN, Bruce AB, Wortman MD, Baker DG, Geracioti TD (1999): The effect of lumbar puncture stress on dopamine and serotonin metabolites in human cerebrospinal fluid. Neurosci Lett 276(1): $25-28$

Hsiao JK, Colison J, Bartko JJ, Doran AR, Konicki PE, Potter WZ, Pickar D (1993a): Monoamine neurotransmitter interactions in drug-free and neuroleptic-treated schizophrenics. Arch Gen Psychiatry 50:606-614

Hsiao JK, Potter WZ, Agren H, Owen RR, Pickar D (1993b): Clinical investigation of monoamine neurotransmitter interactions. Psychopharmacology 112:S76-S84

Iyer RN, Bradberry CW (1996): Serotonin-mediated increase in prefrontal cortex dopamine release: pharmacological characterization. J Pharmacol Exp Ther 277:40-47

Jacobsen LK, Frazier JA, Malhotra AK, Karoum F, McKenna K, Gordon CT, Hamburger SD, Lenane MC, Pickar D, Potter WZ, Rapoport JL (1997): Cerebrospinal fluid monoamine metabolites in childhood-onset schizophrenia. Am J Psychiatry 154:69-74

Jibson M, Faull KF, Csernansky JG (1990): Intercorrelations among monoamine metabolite concentrations in human lumbar CSF are not due to a shared acid transport system. Biol Psychiatry 28:595-602

Kahn RS, Davidson M, Knott P, Stern RG, Apter S, Davis KL (1993): Effect of neuroleptic medication on cerebrospinal fluid monoamine metabolite concentrations in schizophrenia. Arch Gen Psychiatry 50:599-605

Kahn RS, Davidson M, Siever LJ, Sevy S, Davis KL (1994a): Clozapine treatment and its effect on neuroendocrine responses induced by the serotonin agonist, m-chlorophenylpiperazine. Biol Psychiatry 35:909-912
Kahn RS, Harvey PD, Davidson M, Keefe RSE, Apter S, Neale JM, Mohs RC, Davis KL (1994b): Neuropsychological correlates of central monoamine function in chronic schizophrenia: relationship between CSF metabolites and cognitive function. Schizophrenia Research 11:217-224

Kapur S, Remington G (1996): Serotonin-dopamine interaction and its relevance to schizophrenia. Am J Psychiatry 153:466-476

Kay SR, Fiszbein A, Opler LA (1987): The positive and Negative Syndrome Scale (PANSS) for schizophrenia. Schizophr Bull 13:261-276

Kelland MD, Freeman AS, Chiodo LA (1990): Serotonergic afferent regulation of the basic physiology and pharmacological responsiveness of nigrostriatal dopamine neurons. J Pharmacol Exp Ther 253:803-811

Lieberman JA, Kane JM, Safferman AZ, Pollack S, Howard A, Szymanski S, Masiar SJ, Kronig MH, Cooper T, Novacenko H (1994): Predictors of response to clozapine. J Clin Psychiatry 55[9, suppl B]:126-128

Lieberman JA, Koreen AR (1993): Neurochemistry and neuroendocrinology of schizophrenia: a selective review. Schizophr Bull 19:371-429

Lieberman JA, Mailman RB, Duncan G, Sikich L, Chakos M, Nichols DE, Kraus JE (1998): A decade of serotonin research: role of serotonin in treatment of psychosis. Serotonergic basis of antipsychotic drug effects in schizophrenia. Biol Psychiatry 44:1099-1117

Lindstrom LH (1985): Low HVA and normal 5-HIAA CSF levels in drug-free schizophrenic patients compared to healthy volunteers: correlations to symptomatology and family history. Psychiatry Res 14:265-273

Meltzer HY (1989): Clinical studies on the mechanism of action of clozapine: the dopamine-serotonin hypothesis of schizophrenia. Psychopharmacology 99:S18-S27

Moore NA, Leander JD, Benvenga MJ, Gleason SD, Shannon $H$ (1997): Behavioral pharmacology of olanzapine: a novel antipsychotic drug. J Clin Psychiatry 58(suppl 10):37-44

Moore NA, Rees G, Sanger G, Tye NC (1994): Effects of olanzapine and other antipsychotic agents on responding maintained by a conflict schedule. Behav Pharmacol 5:196-202

Nordin C, Eklundh T, Fernstrom V, Swedin A, Zachau AC (1995): Gradients of CSF monoamine metabolites: a comparison between male and female volunteers. J Psych Res 29:133-140

Pickar D, Owen RR, Litman RE, Konicki E, Gutierrez R, Rapaport MH (1992): Clinical and biologic response to clozapine in patients with schizophrenia. Arch Gen Psychiatry 49:345-353

Potter WZ, Manji HK (1993): Are monoamine metabolites in cerebrospinal fluid worth measuring? Arch Gen Psychiatry 50:653-656

Priestley JV, Somogyi P, Cuello AC (1981): Neurotransmitter-specific projection neurons revealed by combining PAP immunohistochemistry with retrograde transport of HRP. Brain Res 220:231-240

Risby ED, Hsiao JW, Sunderland T, Agren H, Rudorfer MV, Potter WZ (1987): The effects of antidepressants on the 
cerebrospinal fluid homovanillic acid/5-hydroxyindoleacetic acid ratio. Clin Pharmacol Ther 42:547-554

Risch SC, Lewine RRJ (1993): Low cerebrospinal fluid homovanillic acid-5-hydroxyindoleacetic acid ratio predicts clozapine efficacy: a replication. Arch Gen Psychiatry 50:670

Risch SC, Lewine RRJ (1995): Clozapine therapy and increases in homovanillic acid. Arch Gen Psychiatry $52: 244$

Roth BL, Meltzer HY (1995): The role of serotonin in schizophrenia. In Bloom FE, Kupfer DJ (eds), Psychopharmacology: the fourth generation of progress. New York, Raven Press, pp 1215-1227

Schmidt CJ, Sorensen SM, Kehne JH, Carr AA, Palfreyman MG (1995): The role of 5-HT2a receptors in antipsychotic activity. Life Sci 56:2209-2222

Sedvall G, Fyro B, Nyback H, Wiesel FA, Wode-Helgodt B (1974): Mass fragmentometric determination of homovanillic acid in lumbar cerebrospinal fluid of schizophrenic patients during treatment with antipsychotic drugs. J Psychiat Res 11:75-80

Sharma RP, Javaid JI, Janicak PG, Davis JM, Faull K (1993): Homovanillic acid in the cerebrospinal fluid: patterns of response after four weeks of neuroleptic treatment. Biol Psychiatry 34:128-134

Sharma R, Javaid JI, Janicak P, Faull K, Comaty J, Davis JM (1989): Plasma and CSF HVA before and after pharmacological treatment. Psychiatry Res 28:97-104

Silver R, LeSauter J, Tresco PA, Lehman MN (1996): A diffusible coupling signal from transplanted suprachiasmatic nucleus controlling circadian locomotor rhythms. Nature 382:810-813

Stanley M, Traskman-Bendz L, Dorovini-Zis K (1985): Correlations between aminergic metabolites simultaneously obtained from human CSF and brain. Life Sci 37:12791286

Szymanski S, Lieberman J, Pollack S, Munne R, Saferman A, Kane J, Kronig M, Cooper T (1993): The dopamine-serotonin relationship in clozapine response. Psychopharmacology 112:S85-S89

Ternaux JP, Hery F, Bourgoin S, Adrien J, Glowinski J, Hamon M (1977): The topographical distribution of serotonergic terminals in the neostriatum of the rat and the caudate nucleus of the cat. Brain Res 121:311-326

Törk I (1991): Anatomy of the serotonergic system. Ann NY Acad Sci 600:9-34

van Kammen DP, van Kammen WB, Mann LS, Seppala T, Linnoila M (1986): Dopamine metabolism in the cerebrospinal fluid of drug-free schizophrenic patients with and without cortical atrophy. Arch Gen Psychiatry 43:978-983

Weinberger DR, Berman KF, Illowsky BP (1988): Physiological dysfunction of dorsolateral prefrontal cortex in schizophrenia III: a new cohort and evidence for monoaminergic mechanism. Arch Gen Psychiatry 45:609-615

Weir RL, Chase TN, Ng LKY, Kopin IJ (1973): 5-Hydroxyindoleacetic acid in the spinal fluid, relative contribution from brain and spinal cord. Brain Res 52:409-412

Westenberg HGM, Verhoeven WMA (1988): CSF monoamine metabolites in patients and controls: support for a bimodal distribution in major affective disorders. Acta Psychiatr Scand 78:541-549

Westerlink BHC, Kikkert RJ (1986): Effects of various centrally acting drugs on the efflux of dopamine metabolites from the rat brain. J Neurochem 46:1145-1152

Wester P, Bergstrom U, Eriksson A, Gezellius C, Hardy J, Winblad B (1990): Ventricular cerebrospinal fluid monoamine transmitter and metabolite concentrations reflect human brain neurochemistry in autopsy cases. J Neurochem 54:1148-1156

Wiesel FA, Nordstrom AL, Farde L, Eriksson B (1994): An open clinical and biochemical study of ritanserin in acute patients with schizophrenia. Psychopharmacology 114:31-38

Wieselgren IM, Lindstrom LH (1998): CSF levels of HVA and 5-HIAA in drug-free schizophrenic patients and healthy controls: a prospective study focused on their predictive value for outcome in schizophrenia. Psychiatry Res 81:101-110

Wode-Helgodt B, Fyro B, Gullberg B, Sedvall G (1977): Effect of chlorpromazine treatment on monoamine metabolite levels in cerebrospinal fluid in psychotic patients. Acta Psychiatr Scand 56:129-142

Wood JH (1980): Neurochemical analysis of cerebrospinal fluid. Neurology 30:645-651 